University of Nebraska - Lincoln

DigitalCommons@University of Nebraska - Lincoln

$12-2009$

\title{
Community Structure and Seasonal Dynamics of Dactylogyrus spp. (Monogenea) on the Fathead Minnow (Pimephales promelas) from the Salt Valley Watershed, Lancaster County, Nebraska
}

Alaine Knipes

University of Nebraska - Lincoln, lainey244@yahoo.com

John J. Janovy Jr.

University of Nebraska - Lincoln, jjanovy1@unl.edu

Follow this and additional works at: https://digitalcommons.unl.edu/bioscijanovy

Part of the Parasitology Commons

Knipes, Alaine and Janovy, John J. Jr., "Community Structure and Seasonal Dynamics of Dactylogyrus spp. (Monogenea) on the Fathead Minnow (Pimephales promelas) from the Salt Valley Watershed, Lancaster County, Nebraska" (2009). John Janovy Publications. 63.

https://digitalcommons.unl.edu/bioscijanovy/63

This Article is brought to you for free and open access by the Papers in the Biological Sciences at DigitalCommons@University of Nebraska - Lincoln. It has been accepted for inclusion in John Janovy Publications by an authorized administrator of DigitalCommons@University of Nebraska - Lincoln. 


\title{
COMMUNITY STRUCTURE AND SEASONAL DYNAMICS OF DACTYLOGYRUS SPP. (MONOGENEA) ON THE FATHEAD MINNOW (PIMEPHALES PROMELAS) FROM THE SALT VALLEY WATERSHED, LANCASTER COUNTY, NEBRASKA
}

\author{
Alaine K. Knipes and John Janovy, Jr. \\ School of Biological Sciences, University of Nebraska-Lincoln, Lincoln, Nebraska 68588. e-mail: alaineknipes@huskers.unl.edu
}

\begin{abstract}
The gill monogene communities of Pimephales promelas (fathead minnow) in 3 distinct sites on converging streams were investigated from 2004 to 2006 in 3 different seasons. Thirty collections of $P$. promelas were made in southeastern Nebraska along 3 converging tributaries: Elk Creek $\left(40.88534^{\circ} \mathrm{N}, 96.83366^{\circ} \mathrm{W}\right)$, West Oak Creek $\left(40.9082^{\circ} \mathrm{N}, 96.81432^{\circ} \mathrm{W}\right)$, and Oak Creek $\left(40.91402^{\circ} \mathrm{N}\right.$, $\left.96.770583^{\circ} \mathrm{W}\right)$, Lancaster County, Nebraska. In all, 103 P. promelas were collected from Elk Creek, 115 from West Oak Creek, and 78 from Oak Creek and examined for gill monogenes. Among the P. promelas collected, 93.5\% were infected with up to 3 species of Dactylogyrus, including Dactylogyrus simplex Mizelle, 1937, Dactylogyrus bychowskyi Mizelle, 1937, and Dactylogyrus pectenatus Mayes, 1977. Mean intensities at Elk Creek, West Oak Creek, and Oak Creek were 17.6, 22.8, and 25.1, and prevalences 88, 95, and 97\%, respectively. At these 3 sites: (1) P. promelas does not share Dactylogyrus species with Semotilus atromaculatus (Creek chub) or Notropis stramineus (Sand shiner); (2) fish size and sex are not predictive of Dactylogyrus infection; (3) Dactylogyrus spp. vary (not always predictably) in their seasonal occurrence; (4) populations of Dactylogyrus spp. respond to environmental differences among sites; and (5) the community structure of Dactylogyrus spp. (order of abundance) is independent of environment.
\end{abstract}

Dactylogyrus Diesing, 1850 (Platyhelminthes: Monogenoidea), is a highly diverse genus with more than 900 described species that are parasitic primarily on gills of cyprinid fishes, the largest and widest continuously distributed fish family in the world's fresh waters (Gibson et al., 1996; Nelson, 2006). More than 131 Dactylogyrus species have been reported from North America (Gibson et al., 1996). The fathead minnow, Pimephales promelas Rafinesque, 1820, is a North American cyprinid commonly reared for fishing bait and has a parasite fauna that is well documented (Hoffman, 1999; Weichman and Janovy, 2000). This minnow occurs in streams with diverse characteristics and thus is a good candidate for use in studies aimed at discovering the roles environment and fish distribution play in structuring monogene populations and communities.

Weichman and Janovy (2000) described the gill monogene community of $P$. promelas in 2 diverging first-order streams in Lancaster County, Nebraska, from April to October 1998. They found 3 species of Dactylogyrus occurring on fathead minnows, including Dactylogyrus simplex, Mizelle, 1937, Dactylogyrus bychowskyi, Mizelle, 1937, and Dactylogyrus pectenatus Mayes, 1977. The distribution of larval trematodes ("blackspot") on these same hosts indicated that fish were more or less restricted to certain tributaries of the drainage (Weichman and Janovy, 2000), suggesting that their monogene communities might also reveal differences attributable to isolation and habitat effects. Unpublished blackspot data from the present study are consistent with those of Weichman and Janovy (2000).

Dactylogyrus spp. are ectoparasites with direct life cycles. Each individual monogene on the gills is the result of a separate encounter with an infective stage, and, when that individual monogene dies, it will fall off. It is generally accepted that the life spans of Dactylogyrus spp. are shorter than those of their fish hosts. Therefore, individual fish will continually lose and gain gill monogenes so that seasonal occurrence data may be indicative of the abundance of the infective stage in the environment.

A high degree of host specificity, characteristic of Dactylogyrus spp., reveals opportunities for, and suggests mechanisms of, parasite dispersal through the environment because those

Received 14 May 2009; revised 12 June 2009; accepted 10 July 2009. DOI: 10.1645/GE-2166.1 parasites are bound by their particular host's movements through that habitat. When a host's movement is restricted, the movements of its Dactylogyrus species should be similarly restricted. Although stable environmental and host conditions might be expected to yield stable parasite populations, variations in environmental conditions, namely, site or seasonal differences in water temperature and flow rate, might be expected to have important impacts on the behavior of fish and the distribution of their parasites in lotic systems. Thus, a study of the ways in which 3 congeneric species of parasites distribute themselves among fish of a single species at 3 abiotically different, but geographically proximate, streams will provide insight into the ways in which populations of parasite species respond to environmental conditions and distribute themselves in nature.

The purpose of the present study was to explore communities of Dactylogyrus spp. in an effort to understand how, despite variations in transmission conditions, the parasites are maintained in the environment. We describe seasonal population dynamics and community structure of 3 Dactylogyrus spp. in 3 distinct sites on converging streams in southeastern Nebraska over a period of $3 \mathrm{yr}$. The study sought to determine (1) host specificity of Dactylogyrus spp. infecting P. promelas within the 3 -stream system, (2) the role of host demographics (size, sex) in providing structure to populations of Dactylogyrus species, (3) seasonal and yearly dynamics of Dactylogyrus spp. populations within sites, (4) population structure differences of Dactylogyrus spp. within sites, and (5) population and community structure (order of abundance) of Dactylogyrus spp. among sites. In particular, this study tested the following null hypotheses: (1) no difference in abundance, intensity, and prevalence among 3 congeners coexisting within sites and (2) no difference in community structure (order of abundance) of 3 congeners among 3 distinct sites. Rejection of the null hypotheses would reveal innate parasite species differences in fecundity and transmission mechanisms, thus providing insight into factors contributing to species diversification within a genus of monogenes. This study of seasonal dynamics constitutes the first multisite, multiyear study of a complex community of Dactylogyrus spp. on a native North American cyprinid species.

This study, therefore, tests the biological hypothesis that closely related species, with direct aquatic life cycles, respond differently 
to shared environmental conditions. Substantial fluctuations in stream flow and stable differences between streams provide the abiotic conditions necessary for testing such a hypothesis (Janovy et al., 1997).

\section{MATERIALS AND METHODS}

A total of 296 P. promelas was examined. Minnows were collected by seine from Elk Creek (Elk) $\left(40.88534^{\circ} \mathrm{N}, 96.83366^{\circ} \mathrm{W}\right)$, West Oak Creek (West Oak) $\left(40.9082^{\circ} \mathrm{N}, 96.81432^{\circ} \mathrm{W}\right)$, and Oak Creek (Oak) $\left(40.91402^{\circ} \mathrm{N}\right.$ $\left.96.770583^{\circ} \mathrm{W}\right)$, Lancaster County, Nebraska, between July 2004 and October 2006. Sample sizes were dictated by the number of fish captured and by the number that could be examined within $48 \mathrm{hr}$ of capture. Fish were brought to the laboratory at the University of Nebraska-Lincoln in buckets with aerators and dissected within $48 \mathrm{hr}$ of collection. All fish were identified according to Plieger (1997). Fish were measured for standard length (STL) and total length (TTL), and sexed, and the gills removed and placed in 1:4,000 formalin (Kritsky et al., 1986).

Monogenes were brushed from the host gills and preserved in alcoholformalin-acetic acid according to Pritchard and Kruse (1982). They were then washed in 70\% ethyl alcohol (ETOH), stained with Semichon's acetocarmine, dehydrated through an ETOH series, cleared in xylene, and permanently mounted on slides with Damar's balsam (Spectrum Chemical, Gardena, California). Living worms also were studied and recorded using video and digital photography. Monogene identification was based on comparison of copulatory structures and on measurements of scelerotized hamuli, hooks, and connective bars of the haptor (Murith and Beverley-Burton, 1985), as found in original species descriptions (Mizelle, 1937; Mayes, 1976, 1977).

Population structure was described as prevalence (PR), mean abundance (MA), and mean intensity (MI), using terminology of Bush et al. (1997). Community structure was described as order of abundance and species richness. Richness is the number of Dactylogyrus species occurring on an individual fish. Host STL and TTL were measured for each fish, and STL alone was statistically deemed to be the best measure of host size. All values are reported as mean \pm 1 standard deviation (SD).

The chi-square test was used to compare PR within and among Dactylogyrus spp., among seasons, and among sites. The chi-square test was also used to compare PR of Dactylogyrus spp. between male and female hosts. Student's $t$-test was used to compare differences in mean abundance among Dactylogyrus spp., among seasons, and among sites. Total MA and MI of the 3 Dactylogyrus spp. were compared among sites using ANOVA. Approximate $t$-tests were calculated when variances were heteroscedastic (Sokal and Rohlf, 1995). Bonferroni corrections based on number of comparisons were used, i.e., testing at significance level of $0.05 /$ $3=0.017$, to safeguard against false significances due to multiple tests on the same data. Pearson's correlation was used to determine relationships among host STL and Dactylogyrus abundance, as well as to determine relationships among host STL and species richness per individual host.

Environmental data were recorded 4 times in 2005 and twice in 2006, at all 3 collection sites. Air and water temperatures were measured using a Fisherbrand ${ }^{\circledR}$ glass thermometer (Fisher, Pittsburgh, Pennsylvania). Depth and width at collection sites were measured using a tape measure. Flow rate was measured using a standard USGS Top Setting Wading Rod with a Pygmy Current Meter. The $\mathrm{pH}$ of water was measured using a pocket-sized $\mathrm{pHep}^{\circledR}$ meter. The electrical conductivity (EC) of water was measured using a DiST WP conductivity/TDS meter. Water samples were brought back to the University of Nebraska-Lincoln in sterile 32-oz Nalgene ${ }^{\circledR}$ containers. In the lab, heterotrophic plate count (HPC) was measured using the IDEXX SimPlate for HPC method. Following the 48$\mathrm{hr}$ incubation period, SimPlates were examined for fluorescing wells, each of which corresponded to most probable number of total waterborne bacteria in the water sample.

\section{RESULTS}

\section{General observations}

A total of 5,976 monogenes of Dactylogyrus was removed from the gills of 276 infected $P$. promelas examined between July 2004 and October 2006. In total, 3,525 worms from 210 P. promelas were identified to species; 40 of those worms were immature and identifiable only to the generic level. At all 3 collection sites, the gill parasite community comprised 3 species, including $D$. simplex, $D$. bychowskyi, and D. pectenatus. The 3 Dactylogyrus species found on $P$. promelas were never found on either of the 2 other fish species examined (Notropis stramineus, $\mathrm{n}=129$; Semotilus atromaculatus, $\mathrm{n}=109)$ in $3 \mathrm{yr}$ of collections. One species $(D$. rubellus) was found on Notropis stramineus, and 3 species (D. tenax, D. microphallus, and D. attenuatus) were found on Semotilus atromaculatus. In $3 \mathrm{yr}$, none of the 6 species from $N$. stramineus and $S$. atromaculatus was ever found on $P$. promelas.

Dactylogyrus species richness on $P$. promelas was $2.10 \pm 1.08$ species per fish. Overall PR (based on $\mathrm{n}=210$ P. promelas) was $92.1 \%$, MA was $20.40 \pm 22.82$, and MI was $22.20 \pm 22.95$. In total, P. promelas were infected with zero $(9.1 \%), 1(19.1 \%), 2$ $(28.6 \%)$, or $3(43.3 \%)$ species of Dactylogyrus. The order of abundance of Dactylogyrus spp. was stable in all collections at all sites, with the exception of the summer of 2004 at Elk and fall 2004 at West Oak.

\section{Site data}

The 3 collection sites differ in their average air and water temperature, $\mathrm{pH}$, width and depth, flow rate, HPC, turbidity, and EC (Table I). All 3 sites are located in an agricultural area approximately $16 \mathrm{~km}$ outside the Lincoln, Nebraska, city limits, though they differ in their surrounding land use. Elk is narrow, tree lined, and well shaded; West Oak is narrow, among farmed fields, and exposed; and Oak is wide, among farm fields and depressed with steep banks. Although the 3 sites are within the same watershed, they differ in their ability to tolerate stormrelated water level changes. Overall, Elk has the least variable flow rate, whereas both West Oak and Oak are subject to highly variable flow rates.

\section{Host sex and size}

Overall, male fish (mean STL $4.99 \mathrm{~cm} \pm 1.06$ ) were larger than females $(4.90 \mathrm{~cm} \pm 0.77)$. In some collections, males were significantly larger than females; however, the differences were not consistent, and, in 1 collection, females were significantly larger than males (Table II). In some collections, fish at Elk were significantly smaller than fish at Oak and West Oak, though the differences were not consistent and sometimes even reversed (Table III).

There were no significant differences in PR or MA of $D$. simplex, D. bychowskyi, or D. pectenatus between male and female fish in any collection at any site, except at Elk in summer 2005, when females had a significantly higher MA of $D$. pectenatus than males $(t=1.83, P<0.05)$ (Table IV).

At all 3 sites, larger fish had greater total Dactylogyrus abundance than smaller fish. There were significant positive correlations between STL and abundance of D. bychowskyi and D. pectenatus at Elk and West Oak, and between STL and abundance of $D$. simplex at West Oak (Figs. 1,2). There were no significant correlations between STL and abundance of any of the 3 Dactylogyrus spp. at Oak (Fig. 3). Although the null hypothesis of no relationship was rejected in the cases mentioned, the $r^{2}$ values were all less than 0.10 .

There were no significant correlations for STL and Dactylogyrus spp. richness at Elk or Oak $(r=0.002, P>0.05$; and $r=$ 
TABle I. Site data: air temperature, water temperature, $\mathrm{pH}$, depth, width, flow rate, heterotrophic plate count (HPC), turbidity, and electrical conductivity (EC).*

\begin{tabular}{|c|c|c|c|c|c|c|c|c|c|}
\hline Collection site & $\begin{array}{l}\text { Air } \\
\left({ }^{\circ} \mathrm{C}\right)\end{array}$ & $\begin{array}{c}\text { Water } \\
\left({ }^{\circ} \mathrm{C}\right)\end{array}$ & $\mathrm{pH}$ & $\begin{array}{l}\text { Depth } \\
\text { (ft) }\end{array}$ & $\begin{array}{l}\text { Width } \\
\text { (ft) }\end{array}$ & $\begin{array}{c}\text { Flow rate } \\
(\mathrm{ft} / \mathrm{sec})\end{array}$ & $\begin{array}{c}\mathrm{HPC} \\
(\mathrm{MPN} / \mathrm{ml})\end{array}$ & $\begin{array}{c}\text { Turbidity } \\
\text { (NTU) }\end{array}$ & $\begin{array}{c}\mathrm{EC} \\
(\mu \mathrm{S} / \mathrm{cm})\end{array}$ \\
\hline \multicolumn{10}{|l|}{ Elk Creek } \\
\hline \multicolumn{10}{|l|}{2005} \\
\hline May & - & 16.0 & 7.7 & 0.8 & 4.5 & 0.7 & $1.1 \times 10^{4}$ & 21.7 & 0.7 \\
\hline June & 18.5 & 18.0 & 8.2 & 1.5 & 6.5 & 0.5 & - & 76.0 & 0.7 \\
\hline July & 22.5 & 21.0 & 7.8 & 1.3 & 6.8 & 0.2 & $5.1 \times 10^{4}$ & 47.7 & 0.9 \\
\hline August & 25.0 & 23.0 & 8.4 & 1.2 & 6.3 & 0.7 & $1.4 \times 10^{4}$ & 23.4 & 0.9 \\
\hline \multicolumn{10}{|l|}{2006} \\
\hline May & 23.0 & 20.0 & 8.4 & 1.7 & 7.3 & 0.3 & $2.1 \times 10^{4}$ & 16.7 & 0.7 \\
\hline July & 25.0 & 21.0 & 8.7 & 2.5 & - & 0.1 & $1.8 \times 10^{4}$ & 11.8 & 0.9 \\
\hline Total & 22.8 & 19.8 & 8.2 & 1.5 & 6.3 & 0.3 & $2.3 \times 10^{4}$ & 32.9 & 0.8 \\
\hline \multicolumn{10}{|l|}{ West Oak Creek } \\
\hline \multicolumn{10}{|l|}{2005} \\
\hline May & 24.0 & 19.0 & 7.8 & 0.6 & 4.0 & 0.6 & $1.1 \times 10^{4}$ & 29.8 & 0.6 \\
\hline June & 18.5 & 17.5 & 8.0 & 0.3 & 4.0 & 1.6 & - & 901.0 & 0.4 \\
\hline July & 20.0 & 19.5 & 8.2 & 0.8 & 8.4 & 0.2 & $1.4 \times 10^{4}$ & 30.8 & 0.6 \\
\hline August & 27.0 & 21.0 & 8.1 & 0.7 & 8.3 & 0.1 & $1.2 \times 10^{4}$ & 23.3 & 0.6 \\
\hline \multicolumn{10}{|l|}{2006} \\
\hline May & 22.5 & 18.0 & 8.2 & 0.8 & 5.0 & 0.1 & $2.9 \times 10^{4}$ & 21.1 & 0.6 \\
\hline July & 23.0 & 20.0 & 8.2 & 0.8 & 2.7 & 0.1 & $1.7 \times 10^{4}$ & 39.5 & 0.6 \\
\hline Total & 22.5 & 19.1 & 8.1 & 0.7 & 5.4 & 0.5 & $1.7 \times 10^{4}$ & 174.3 & 0.6 \\
\hline \multicolumn{10}{|l|}{ Oak Creek } \\
\hline \multicolumn{10}{|l|}{2005} \\
\hline May & 27.0 & 17.5 & 7.9 & 1.8 & 30.0 & 0.7 & $7.6 \times 10^{3}$ & 74.9 & 1.1 \\
\hline June & 18.5 & 18.5 & 8.0 & 1.5 & 30.0 & 2.1 & - & 679.0 & 0.8 \\
\hline July & 29.0 & 23.0 & 8.2 & 1.0 & 29.5 & 0.8 & $7.4 \times 10^{4}$ & 20.9 & 1.2 \\
\hline August & 32.0 & 25.5 & 8.2 & 1.4 & 30.8 & 0.3 & $2.6 \times 10^{4}$ & 29.9 & 2.1 \\
\hline \multicolumn{10}{|l|}{2006} \\
\hline May & 25.5 & 20.0 & 8.5 & 1.2 & 10.7 & 0.7 & $2.4 \times 10^{4}$ & 25.8 & 1.4 \\
\hline July & 25.0 & 22.0 & 8.7 & 1.3 & - & 0.6 & $2.2 \times 10^{4}$ & 48.8 & 1.1 \\
\hline Total & 26.2 & 21.1 & 8.3 & 1.4 & 26.2 & 0.9 & $3.1 \times 10^{4}$ & 146.6 & 1.3 \\
\hline
\end{tabular}

* MPN/ml = most probable number of microorganisms per milliliter; NTU = nephelometric turbidity units; $\mu \mathrm{S} / \mathrm{cm}=$ micro-Siemens per centimeter.

$0.196, P>0.05$, respectively), but there was a significant positive correlation at West Oak $(r=0.203, P<0.05)$, although again the $r^{2}$ value was less than 0.10 .

\section{Within site comparisons}

Elk Creek: Seventy-five (85.23\%) of 88 P. promelas collected at Elk were infected with Dactylogyrus spp. A total of 709 D. simplex, 261 D. bychowskyi, and 132 D. pectenatus was collected from the gills of 67, 56, and 53 P. promelas, respectively. Overall, Dactylogyrus spp. MA and MI at Elk were $16.36 \pm 17.45$ (range $0-122$ ) and $19.20 \pm 17.41$, respectively.

In all years, $D$. simplex occurred on $P$. promelas in all seasons at Elk (Table V). There were no significant seasonal differences in PR, MA, or MI of D. simplex, except for MA and MI in 2005. At Elk there were no significant between-year differences in PR, MA, or MI of D. simplex, except for PR in fall, and for MA and MI in spring and summer. In all years, D. bychowskyi occurred on $P$. promelas in all seasons at Elk, except in fall 2004. There were no significant seasonal differences in PR, MA, or MI of $D$. bychowskyi, except for PR and MA in 2005. At Elk, there were no significant between-year differences in PR, MA, or MI of $D$. bychowskyi, except for PR and MA in spring and summer. In all years, D. pectenatus occurred on $P$. promelas in all seasons at Elk, except in fall 2004. There were no significant seasonal differences in PR, MA, or MI of D. pectenatus, except for PR and MA in 2005. At Elk, there were no significant between-year differences in PR, MA, or MI of D. pectenatus, except for PR in spring and summer.

At Elk, there were no significant differences in PR, MA, or MI among Dactylogyrus spp. except in spring 2005, summers 2004, 2005, and 2006, and spring 2006 (Table VI).

The MA and MI of $D$. simplex peaked in summer in all years at Elk. The PR of D. simplex peaked in summer in 2004, in fall in 2005, and in spring in 2006. The PR of D. bychowskyi peaked in summer in all years. The MA of $D$. bychowskyi peaked in summer in 2004 and 2005 and in spring in 2006. The MI of D. bychowskyi peaked in summer in 2004, in fall in 2005, and in spring in 2006. The PR of D. pectenatus peaked in summer in all years. The MA of D. pectenatus peaked in summer in 2004 and 2005, and again in the spring in 2006.

West Oak Creek: Seventy-four (96.10\%) of 77 P. promelas collected at West Oak were infected with Dactylogyrus spp. A total of 1,020 D. simplex, 282 D. bychowskyi, and $142 \mathrm{D}$. pectenatus was collected from the gills of 69, 59, and $48 P$. 
TABLE II. Collections of Pimephales promelas: sites, dates, STL (cm), and significance tests.*

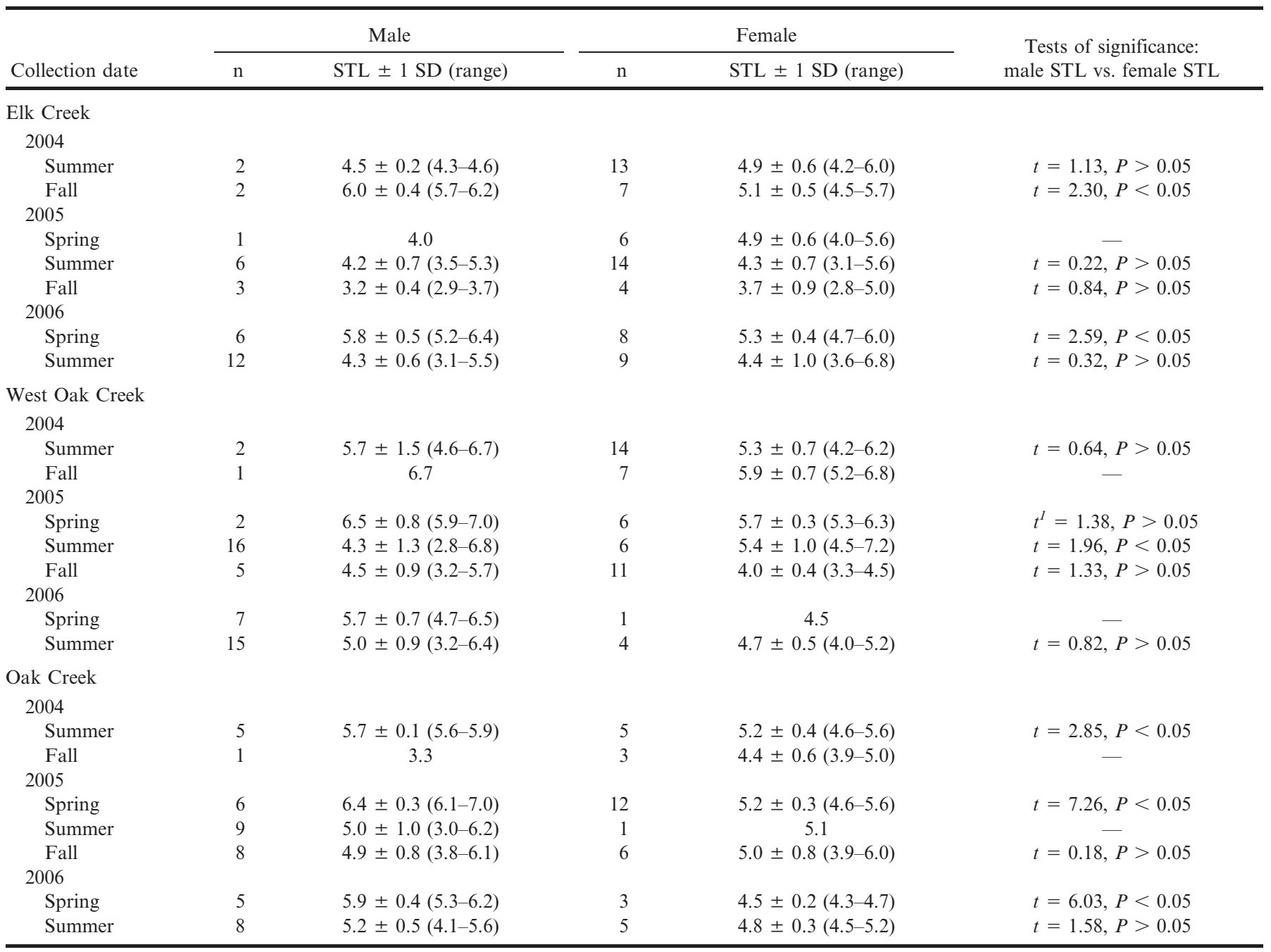

$* \mathrm{SD}=$ standard deviation; STL $=$ standard length.

TABLE III. Standard length $(\mathrm{cm})$ of $P$. promelas: comparisons among collection sites.*

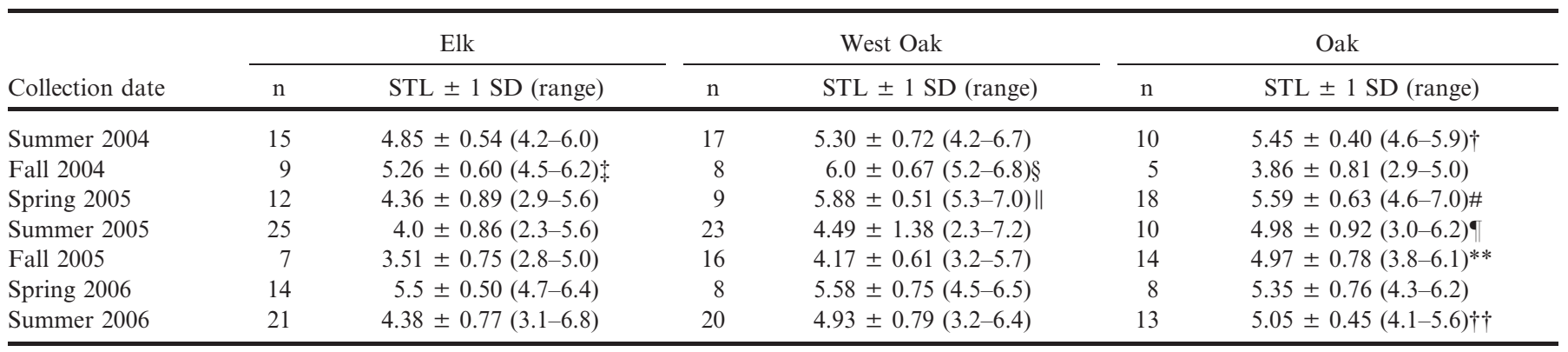

* $\mathrm{SD}=$ standard deviation; STL $=$ standard length. Significance level $P<0.017$.

$\dagger$ OC STL significantly greater than EC, $t=3.02$.

* EC STL significantly greater than OC, $t=3.68$.

$\S$ WC STL significantly greater than OC, $t=5.16$

\| WC STL significantly greater than EC, $t=4.55$.

\# OC STL significantly greater than EC, $t=4.43$

- OC STL significantly greater than EC, $t=2.99$.

** OC STL significantly greater than EC, $t=4.07$. OC STL significantly greater than WC, $t=3.15$

$\dagger$ OC STL significantly greater than EC, $t=3.23$. 


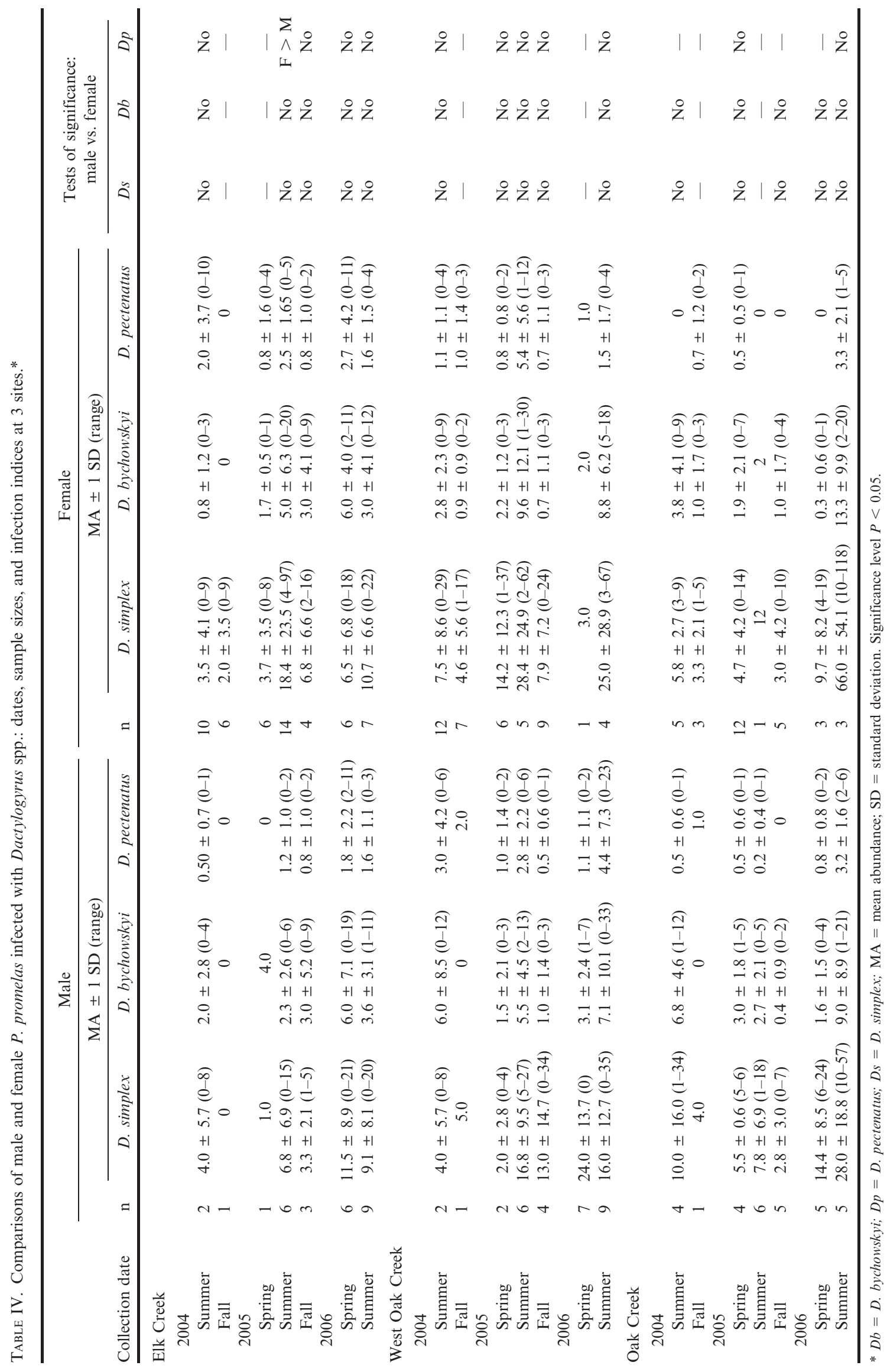




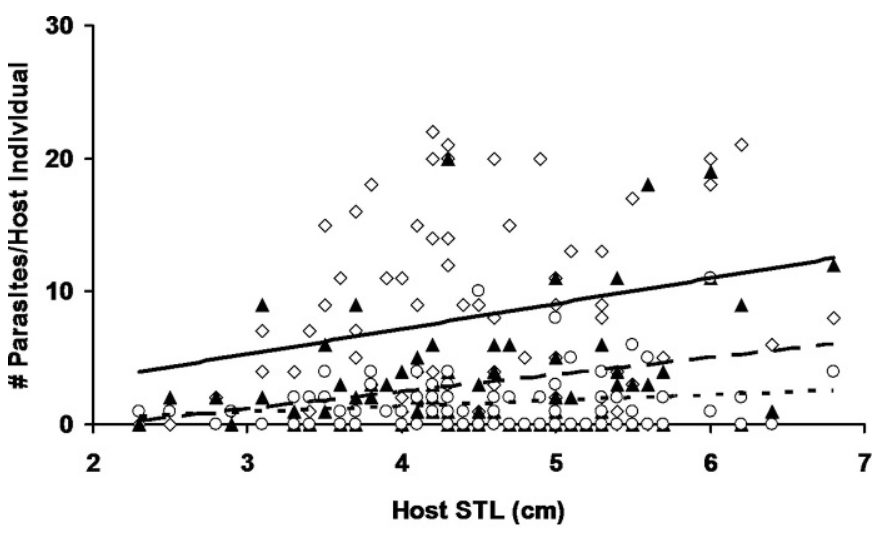

$\diamond$ D. simplex $\triangle D$. bychowskyi $\circ$ D. pectenatus

FIGURE 1. Scatter plots of parasites per host versus host standard length $(\mathrm{cm})$ at Elk Creek. Dactylogyrus simplex, $y=1.90 x-0.41, r^{2}=$ $0.02, P>0.05 ;$ D. bychowskyi, $y=1.28 x-2.68, r^{2}=0.07, P<0.05 ; D$. pectenatus, $y=0.43 x-0.40, r^{2}=0.03, P<0.05$.

promelas, respectively. Overall, Dactylogyrus spp. MA and MI at West Oak were $24.19 \pm 23.05$ (range $0-107$ ) and $25.18 \pm 22.98$, respectively.

In all years, $D$. simplex occurred on $P$. promelas in all seasons at West Oak (Table VII). There were no significant seasonal differences in PR, MA, or MI of D. simplex in any year. At West Oak, there were no significant between-year differences in PR, MA, or MI of D. simplex, except for PR and MA in summer, and $\mathrm{MI}$ in fall. In all years, $D$. bychowskyi occurred on $P$. promelas in all seasons at West Oak. There were no significant seasonal differences in PR of D. bychowskyi, except in 2005 and 2004. At West Oak, there were no significant between-year differences in PR, MA, or MI of D. bychowskyi in any season. In all years $D$. pectenatus occurred on $P$. promelas in all seasons at West Oak. There were no significant seasonal differences in PR, MA, or MI of D. pectenatus, except in 2004 and 2005. At West Oak, there were no significant between-year differences in PR, MA, or MI of D. pectenatus in any season.

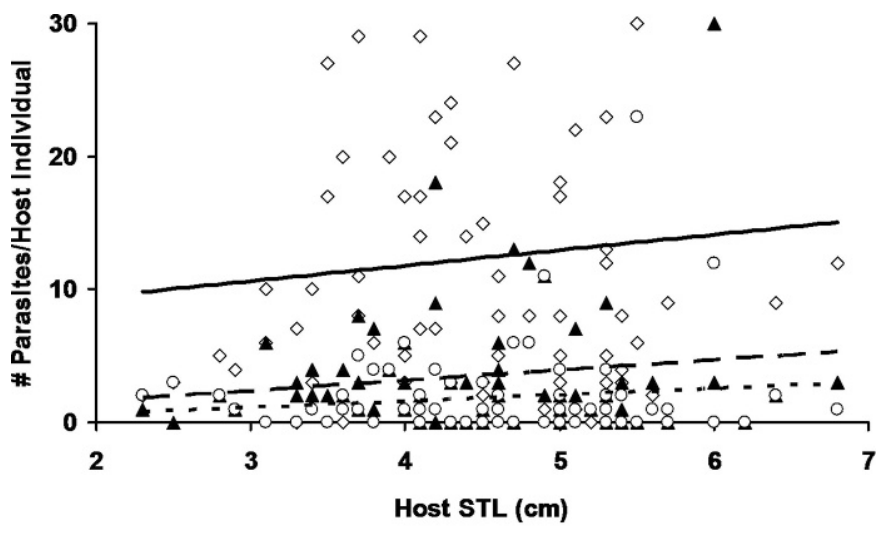

$\diamond D$. simplex $\triangle D$. bychowskyi $\circ D$. pectenatus

FIGURE 2. Scatter plots of parasites per host versus host standard length $(\mathrm{cm})$ at West Oak Creek. Dactylogyrus simplex, $y=3.43 x-5.41, r^{2}$ $=0.06, P<0.05 ;$ D. bychowskyi, $y=1.74 x-5.55, r^{2}=0.09, P<0.05 ; D$. pectenatus, $y=0.85 x-2.62, r^{2}=0.07, P<0.05$.

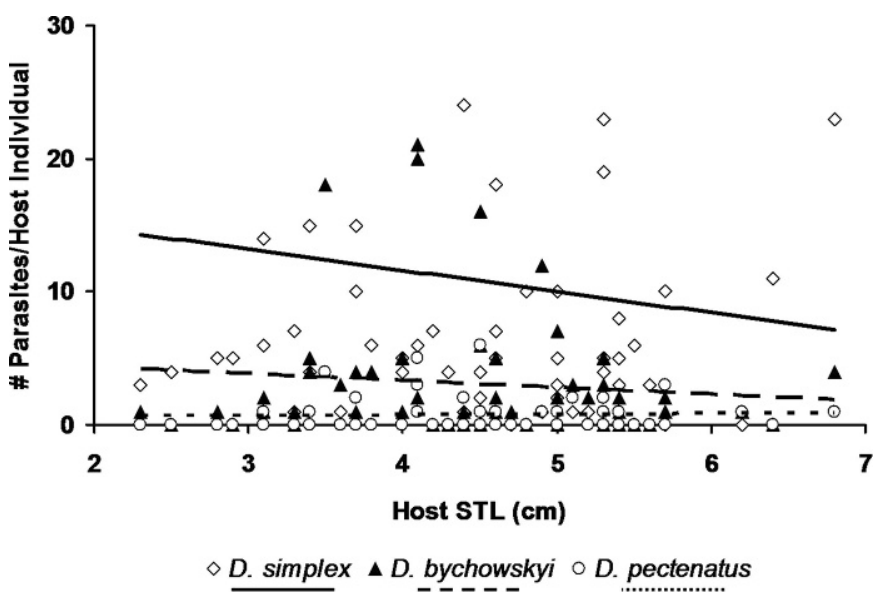

FIGURE 3. Scatter plots of parasites per host versus host standard length $(\mathrm{cm})$ at Oak Creek. Dactylogyrus simplex, $y=-0.33 x-12.54, r^{2}=$ $0.0002, P>0.05 ;$ D. bychowskyi, $y=0.51 x-0.43, r^{2}=0.01, P>0.05 ; D$. pectenatus, $y=0.52 x-0.49, r^{2}=0.001, P>0.05$.

At West Oak, there were no significant differences in PR, MA, or MI among Dactylogyrus spp., except in fall 2005, summers 2004, 2005, and 2006, and springs 2005 and 2006 (Table VIII).

The PR of D. simplex peaked in fall in 2004, in summer in 2005, and in spring in 2006 at West Oak. The MA and MI of D. simplex peaked in summer in 2004 and 2005, and in spring of 2006. The PR of D. bychowskyi peaked in summer in 2004 and 2005, and in spring of 2006. The MA and MI of D. bychowskyi peaked in summer in all years. The PR and MA of D. pectenatus peaked in summer in all years. The MI of D. pectenatus peaked in fall 2004, and in summer 2005 and 2006.

Oak Creek: Sixty-one $(96.83 \%)$ of 63 fathead minnows collected at Oak were infected with Dactylogyrus spp. A total of 692 D. simplex, 203 D. bychowskyi, and 44 D. pectenatus was collected from the gills of 58, 44, and 24 P. promelas, respectively. Overall, Dactylogyrus spp. MA and MI at Oak were $21.51 \pm$ 28.52 (range $0-145$ ) and $22.29 \pm 28.73$, respectively.

In all years, $D$. simplex occurred on $P$. promelas in all seasons at Oak (Table IX). There were no significant seasonal differences in PR, MA, or MI of $D$. simplex, in any year. At Oak, there were no significant between-year differences in PR, MA, or MI of $D$. simplex, except for MA and MI in spring. In all years $D$. bychowskyi occurred on $P$. promelas in all seasons at Oak. There were no significant seasonal differences in PR, MA, or MI of $D$. bychowskyi except PR and MA in 2004, PR in 2005, and MA in 2006. At Oak, there were no significant between-year differences in PR, MA, or MI of D. bychowskyi in any season. In all years, $D$. pectenatus occurred on $P$. promelas in all seasons at Oak, except in fall 2005. There were no significant seasonal differences in PR, MA, or MI of D. pectenatus, except for PR in 2005, and for PR and MA in 2006. At Oak, there were no significant between-year differences in PR, MA, or MI of D. pectenatus, except for PR and MA in summer, and PR in fall. There were no significant between-year differences in MI of $D$. pectenatus in any season. At Oak, there were significant differences in PR, MA, or MI among Dactylogyrus spp. in all collections (Table X).

The PR of D. simplex was $100 \%$ in all seasons in 2004 and 2006 and peaked in summer 2005. The MA and MI of D. simplex peaked in summer in all years. The PR of D. simplex peaked in 
TABle V. Seasonal and between-year comparisons: dates, sample sizes, and infection indices of Dactylogyrus spp. on P. promelas at Elk Creek.*

\begin{tabular}{|c|c|c|c|c|c|c|c|c|c|c|}
\hline \multirow[b]{2}{*}{ Collection date } & \multirow{2}{*}{$\begin{array}{l}\text { No. of } \\
\text { fish }\end{array}$} & \multicolumn{3}{|c|}{ D. simplex } & \multicolumn{3}{|c|}{ D. bychowskyi } & \multicolumn{3}{|c|}{ D. pectenatus } \\
\hline & & PR & $\mathrm{MA} \pm 1 \mathrm{SD}$ & $\mathrm{MI} \pm 1 \mathrm{SD}$ & PR & $\mathrm{MA} \pm 1 \mathrm{SD}$ & $\mathrm{MI} \pm 1 \mathrm{SD}$ & PR & $\mathrm{MA} \pm 1 \mathrm{SD}$ & $\mathrm{MI} \pm 1 \mathrm{SD}$ \\
\hline Summer 2004 & 12 & 50.0 & $3.6 \pm 4.1$ & $7.2 \pm 2.6$ & 41.7 & $1.0 \pm 1.5$ & $2.4 \pm 1.3$ & 41.7 & $1.8 \pm 3.4$ & $4.2 \pm 4.4$ \\
\hline Fall 2004 & 7 & 42.9 & $1.7 \pm 3.3$ & $4.0 \pm 4.4$ & 0.0 & 0.0 & 0.0 & 0.0 & 0.0 & 0.0 \\
\hline Spring 2005 & 9 & 88.9 & $2.8 \pm 3.1$ & $3.1 \pm 3.1$ & 22.2 & $0.6 \pm 1.3$ & $2.5 \pm 2.1$ & 22.2 & $0.6 \pm 1.3 t$ & $2.5 \pm 2.1$ \\
\hline Summer 2005 & 24 & 83.3 & $13.6 \pm 19.2 \S$ & $16.4 \pm 19.9 \|$ & 79.2\# & $4.1 \pm 5.1 \Phi$ & $5.2 \pm 5.3$ & $87.5^{* *}$ & $2.1 \pm 1.5 \dagger \dagger$ & $2.4 \pm 1.4$ \\
\hline Fall 2005 & 7 & $100.0 t t$ & $5.3 \pm 5.2$ & $5.3 \pm 5.2$ & 57.1 & $3.0 \pm 4.2$ & $5.3 \pm 4.4$ & 42.9 & $0.6 \pm 0.8$ & $1.3 \pm 0.6$ \\
\hline Spring 2006 & 12 & 83.3 & $9.0 \pm 8.0 \S \S$ & $10.8 \pm 7.5\|\|$ & $91.7 \# \#$ & $6.0 \pm 5.5-9$ & $6.6 \pm 5.4$ & $66.7 * * *$ & $2.3 \pm 3.2$ & $3.4 \pm 3.5$ \\
\hline Summer 2006 & 16 & 81.3 & $9.8 \pm 7.3 \dagger \dagger \dagger$ & $12.1 \pm 6.1+t t$ & $93.8 \S \S \S$ & $3.3 \pm 3.4\|\| \|$ & $3.5 \pm 3.4$ & 75.0 & $1.6 \pm 1.3$ & $2.1 \pm 1.0$ \\
\hline Total & 88 & 76.1 & $8.1 \pm 11.1$ & $10.6 \pm 12.5$ & 63.6 & $3.0 \pm 3.5$ & $4.7 \pm 3.6$ & 60.0 & $1.5 \pm 2.1$ & $2.6 \pm 2.2$ \\
\hline
\end{tabular}

\footnotetext{
* $\mathrm{MA}=$ mean abundance; $\mathrm{MI}=$ mean intensity; $\mathrm{PR}=$ prevalence; $\mathrm{SD}=$ standard deviation. Significance level $P<0.017$.

In 2005, PR of $D p$ significantly greater in summer than spring, $\chi^{2}=13.21$.

In spring, PR of $D p$ significantly greater in 2005 than $2004, \chi^{2}=8.38$.

In 2005, MA of $D s$ significantly greater in summer than spring, $t^{1}=2.68$. In summer, MA of $D s$ significantly greater in 2005 than $2004, t^{1}=2.46$.

In 2005, MI of $D s$ significantly greater in summer than spring, $t^{I}=2.88$. In 2005, MI of $D$ s significantly greater in summer than fall, $t^{1}=2.28$.

\# In 2005, PR of $D b$ significantly greater in summer than spring, $\chi^{2}=9.17$

- In 2005, MA of $D b$ significantly greater in summer than spring, $t^{1}=3.10$. In summer, MA of $D b$ significantly greater in 2005 than $2004, t^{l}=2.73$.

** In 2005, PR of $D p$ significantly greater in summer than fall, $\chi^{2}=6.18$. In summer, PR of $D p$ significantly greater in 2005 than $2004, \chi^{2}=8.38$.

$\dagger$ In 2005, MA of $D p$ significantly greater in summer than spring, $t=2.64$. In 2005, MA of $D p$ significantly greater in summer than fall, $t=2.50$.

+ In fall, PR of $D s$ significantly greater in 2005 than $2004, \chi^{2}=5.6(P<0.05)$.

$\S \S \quad$ In spring, MA of $D s$ significantly greater in 2006 than $2005, t^{l}=2.46$.

\|| $\|$ In spring, MI of $D s$ significantly greater in 2006 than $2005, t^{I}=2.93$.

\#\# In spring, PR significantly greater in 2006 than $2005, \chi^{2}=10.51$

I In spring, MA of $D b$ significantly greater in 2006 than $2005, t^{1}=2.31$.

*** In spring, PR of $D p$ significantly greater in 2006 than $2005, \chi^{2}=4.07(P<0.05)$

$+\dagger$ In summer, MA of $D s$ significantly greater in 2006 than $2004, t^{1}=2.87$

+1 In summer, MI of $D s$ significantly greater in 2006 than $2004, t^{I}=2.48$.

$\S \S \S$ In summer, PR of $D b$ significantly greater in 2006 than $2004, \chi^{2}=9.11$.

|| || || In summer, MA of $D b$ significantly greater in 2006 than $2004, t^{1}=2.41$.
}

summer in 2004 and 2006 and in spring in 2005. The MA and MI of $D$. bychowskyi peaked in summer in all years. The PR of $D$. pectenatus peaked in fall in 2004, spring in 2005, and summer in 2006. The MA and MI of D. pectenatus peaked in fall in 2004, spring 2005, and summer 2006.

\section{Among site comparisons}

In all years the PR, MA, and MI of $D$. simplex did not differ significantly among sites in any season except in summer 2004 when PR was significantly higher at Oak than at Elk $\left(\chi^{2}=6.30, P\right.$ $<0.017$ ), in fall 2004 when PR was significantly higher at West Oak than at Elk $\left(\chi^{2}=6.23, P<0.017\right)$, and in spring of 2006 when MA was significantly higher at West Oak than at Elk $\left(t^{1}{ }_{s}=\right.$ 2.44, $P<0.017$ ). Total MA and MI of $D$. simplex did not differ significantly among Elk, West Oak, and Oak $\left(F_{2,226}=2.57, P=\right.$ $0.08 ; F_{2,191}=1.34, P=0.26$, respectively).

The PR, MA, and MI of D. bychowskyi did not differ significantly among sites in any season except in spring 2005 when PR was significantly higher at Oak than at Elk $\left(\chi^{2}=10.65\right.$,

TABLE VI. Community structure: dates, sample sizes, and infection indices of 3 Dactylogyrus spp. on P. promelas at Elk Creek.*

\begin{tabular}{|c|c|c|c|c|c|c|c|c|c|c|}
\hline \multirow{3}{*}{$\begin{array}{l}\text { Collection date } \\
\text { Summer } 2004\end{array}$} & \multirow{3}{*}{$\frac{\text { No. of fish }}{12}$} & \multicolumn{3}{|c|}{ D. simplex } & \multicolumn{3}{|c|}{ D. bychowskyi } & \multicolumn{3}{|c|}{ D. pectenatus } \\
\hline & & \multirow{2}{*}{$\frac{\mathrm{PR}}{50.0}$} & \multirow{2}{*}{$\frac{\mathrm{MA} \pm 1 \mathrm{SD}}{3.6 \pm 4.1}$} & \multirow{2}{*}{$\frac{\mathrm{MI} \pm 1 \mathrm{SD}}{7.2 \pm 2.6 \dagger}$} & \multirow{2}{*}{$\frac{\mathrm{PR}}{41.7}$} & \multicolumn{2}{|c|}{$\mathrm{MA} \pm 1 \mathrm{SD} \mathrm{MI} \pm 1 \mathrm{SD}$} & \multirow{2}{*}{$\frac{\mathrm{PR}}{41.7}$} & \multicolumn{2}{|c|}{$\mathrm{MA} \pm 1 \mathrm{SD} \mathrm{MI} \pm 1 \mathrm{SD}$} \\
\hline & & & & & & $1.00 \pm 1.5$ & $2.4 \pm 1.3$ & & $1.8 \pm 3.4$ & $4.2 \pm 4.4$ \\
\hline Fall 2004 & 7 & 42.9 & $1.7 \pm 3.3$ & $4.0 \pm 4.4$ & 0.0 & 0.0 & 0.0 & 0.0 & 0.0 & 0.0 \\
\hline Spring 2005 & 9 & $88.9 \ddagger$ & $2.8 \pm 3.1 \S$ & $3.1 \pm 3.1$ & 22.2 & $0.6 \pm 1.3$ & $2.5 \pm 2.1$ & 22.2 & $0.6 \pm 1.3$ & $2.5 \pm 2.1$ \\
\hline Summer 2005 & 24 & $83.3^{\circ}$ & $13.6 \pm 19.2 \|$ & $16.4 \pm 19.9 \#$ & 79.2 & $4.1 \pm 5.1$ & $5.2 \pm 5.3$ & 87.5 & $2.1 \pm 1.5$ & $2.4 \pm 1.4$ \\
\hline Fall 2005 & 7 & 100.0 & $5.3 \pm 5.2$ & $5.3 \pm 5.2$ & 57.1 & $3.0 \pm 4.2$ & $5.3 \pm 4.4$ & 42.9 & $0.6 \pm 0.8$ & $1.3 \pm 0.6$ \\
\hline Spring 2006 & 12 & 83.3 & $9.0 \pm 8.0-$ & $10.8 \pm 7.5^{* *}$ & 91.7 & $6.0 \pm 5.5$ & $6.6 \pm 5.4$ & 66.7 & $2.3 \pm 3.2$ & $3.4 \pm 3.5$ \\
\hline Summer 2006 & 16 & 81.3 & $9.8 \pm 7.3 \dagger \dagger$ & $12.1 \pm 6.1 t t$ & 93.8 & $3.3 \pm 3.4$ & $3.5 \pm 3.4$ & 75.0 & $1.6 \pm 1.3$ & $2.1 \pm 1.0$ \\
\hline Total & 88 & 76.1 & $8.1 \pm 11.1$ & $10.6 \pm 12.5$ & 63.6 & $3.0 \pm 3.5$ & $4.7 \pm 3.6$ & 60.0 & $1.5 \pm 2.1$ & $2.6 \pm 2.2$ \\
\hline
\end{tabular}

* $\mathrm{MA}=$ mean abundance; $\mathrm{MI}=$ mean intensity; $\mathrm{PR}=$ prevalence; $\mathrm{SD}=$ standard deviation. Significance level $P<0.017$.

$\dagger$ MI of $D s$ significantly greater than $D b, t=3.73$.

+ PR of $D s$ significantly greater than $D b, \chi^{2}=8.1$. PR of $D s$ significantly greater than $D p, \chi^{2}=8.1$.

$\S$ MA of $D s$ significantly greater than $D b, t=1.93$. MA of $D s$ significantly greater than $D p, t=1.93$.

\| MA of $D s$ significantly greater than $D b, t=2.36$. MA of $D s$ significantly greater than $D p, t=2.94$

\# MI of $D s$ significantly greater than $D b, t=2.42$. MI of $D s$ significantly greater than $D p, t=3.13$.

- MA of $D s$ significantly greater than $D p, t=2.71$

** MI of $D s$ significantly greater than $D p, t=2.57$.

$\dagger$ MA of $D s$ significantly greater than $D b, t=3.23$. MA of $D s$ significantly greater than $D p, t=4.47$.

t5 MI of $D s$ significantly greater than $D b, t=4.68$. MI of $D s$ significantly greater than $D p, t=5.87$. 
TABLE VII. Seasonal and between-year comparisons: dates, sample sizes, and infection indices of Dactylogyrus spp. on P. promelas at West Oak Creek.*

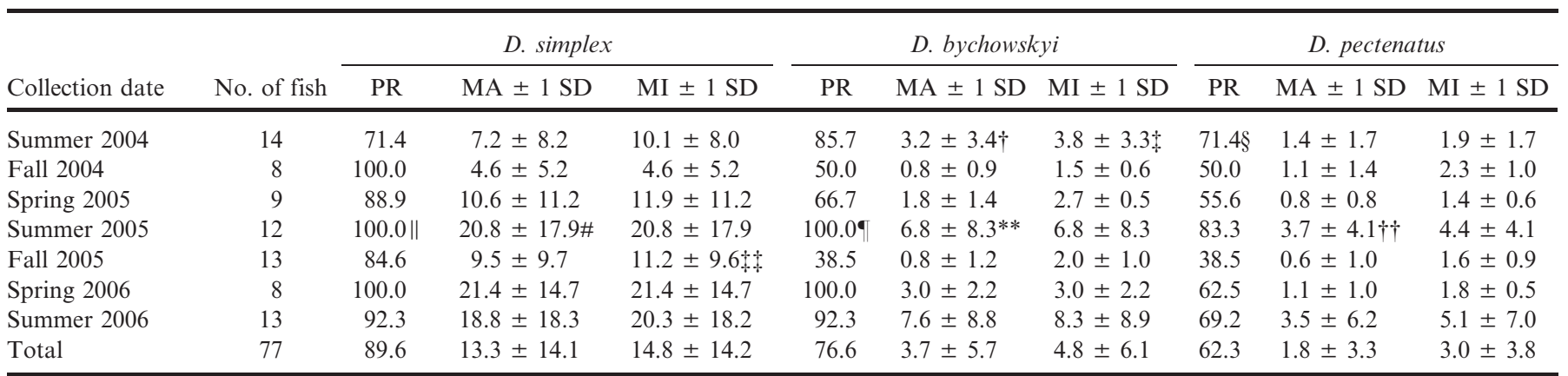

* $\mathrm{MA}=$ mean abundance; $\mathrm{MI}=$ mean intensity; $\mathrm{PR}=$ prevalence; $\mathrm{SD}=$ standard deviation. Significance level $P<0.017$.

$\dagger$ In 2004, MA of $D b$ significantly greater in summer than fall, $t^{I}=2.59(P<0.05)$.

* In 2004, MI of $D b$ significantly greater in summer than fall, $t^{l}=2.24(P<0.05)$.

$\S$ In 2004, PR of $D p$ significantly greater in summer than fall, $\chi^{2}=5.14(P<0.05)$.

$\|$ In summer, PR of $D s$ significantly greater in 2005 than $2004, \chi^{2}=4.05(P<0.05)$

\# In summer, MA of $D s$ significantly greater in 2005 than $2004, t^{l}=2.41$.

- In 2005, PR of $D b$ significantly greater in summer than fall, $\chi^{2}=10.86$.

** In 2005, MA of $D b$ significantly greater in summer than fall, $t^{1}=2.50$.

H In 2005, MA of $D p$ significantly greater in summer than fall, $t^{1}=2.53$

t+ In fall, MA of $D s$ significantly greater in 2005 than $2004, t^{l}=1.75(P<0.05)$.

$P<0.017$ ), in summer of 2004 when MA was significantly higher at Oak than at Elk $\left(t^{1}=2.74, P<0.017\right)$, and in spring 2006 when MA and MI were significantly higher at Elk than at Oak $\left(t^{l}{ }_{s}=2.94, P<0.017 ; t^{l}{ }_{s}=2.74, P<0.017\right.$, respectively). Total MA and MI of $D$. bychowskyi did not differ significantly among Elk, West Oak, and Oak $\left(F_{2,226}=0.42, P=0.66 ; F_{2,156}=0.01, P\right.$ $=0.99$, respectively).

The PR, MA, and MI of D. pectenatus did not differ significantly among sites in any season except in summer 2005 when PR and MA were significantly higher at West Oak than Oak $\left(\chi^{2}=8.65, P<0.017 ; t^{1}=2.97, P<0.017\right.$, respectively), significantly higher at Elk than Oak $\left(\chi^{2}=8.65, P<0.017 ; t^{1}{ }_{s}=\right.$
5.65, $P<0.017$, respectively), and in summer 2004 when MA was significantly higher at West Oak than at Oak $\left(t^{1}{ }_{s}=2.39, P<\right.$ 0.017). Total MI of $D$. pectenatus did not differ significantly among Elk, West Oak, and Oak $\left(F_{2,120}=1.25, P=0.29\right)$; however, MA did differ significantly $\left(F_{2,226}=4.15, P=0.017\right)$.

\section{Community structure}

At Elk, abundance of $D$. simplex was significantly positively correlated with abundance of $D$. bychowskyi and with abundance of $D$. pectenatus. Abundance of $D$. bychowskyi was significantly positively correlated with abundance of $D$. pectenatus (Table XI).

TABLE VIII. Community structure: dates, sample sizes, and infection indices of 3 Dactylogyrus spp. on P. promelas at West Oak Creek.*

\begin{tabular}{|c|c|c|c|c|c|c|c|c|c|c|}
\hline Collection date & $\begin{array}{l}\text { No. of } \\
\text { fish }\end{array}$ & \multicolumn{3}{|c|}{ D. simplex } & \multicolumn{3}{|c|}{ D. bychowskyi } & \multicolumn{3}{|c|}{ D. pectenatus } \\
\hline Summer 2004 & 14 & 71.4 & $7.2 \pm 8.2 \dagger$ & $10.1 \pm 8.0 \%$ & 85.7 & $3.2 \pm 3.4$ & $3.8 \pm 3.3$ & 71.4 & $1.4 \pm 1.7$ & $1.9 \pm 1.7$ \\
\hline Spring 2005 & 9 & 88.9 & $10.6 \pm 11.2 \S$ & $11.9 \pm 11.2 \|$ & 66.7 & $1.8 \pm 1.4$ & $2.7 \pm 0.5 \#$ & 55.6 & $0.8 \pm 0.8$ & $1.4 \pm 0.6$ \\
\hline Summer 2005 & 12 & 100.0 & $20.8 \pm 17.9$ & $20.8 \pm 17.9^{* *}$ & 100.0 & $6.8 \pm 8.3$ & $6.8 \pm 8.3$ & 83.3 & $3.7 \pm 4.1$ & $4.4 \pm 4.1$ \\
\hline Fall 2005 & 13 & $84.6+\dagger$ & $9.5 \pm 9.7 t t$ & $11.2 \pm 9.6 \S \S$ & 38.5 & $0.8 \pm 1.2$ & $2.0 \pm 1.0$ & 38.5 & $0.6 \pm 1.0$ & $1.6 \pm 0.9$ \\
\hline Total & 77 & 89.6 & $13.3 \pm 14.1$ & $14.8 \pm 14.2$ & 76.6 & $3.7 \pm 5.7$ & $4.8 \pm 6.1$ & 62.3 & $1.8 \pm 3.3$ & $3.0 \pm 3.8$ \\
\hline
\end{tabular}

* $\quad \mathrm{MA}=$ mean abundance; $\mathrm{MI}=$ mean intensity; $\mathrm{PR}=$ prevalence; $\mathrm{SD}=$ standard deviation. Significance level $P<0.017$.

$\uparrow \quad$ MA of $D s$ significantly greater than $D p, t=2.63$.

* $\quad$ MI of $D s$ significantly greater than $D p, t=3.18$.

$\S \quad$ MA of $D s$ significantly greater than $D p, t=2.61$

\| MI of $D s$ significantly greater than $D p, t=2.64$.

\# $\quad$ MI of $D b$ significantly greater than $D p, t=3.94$.

- MA of $D s$ significantly greater than $D b, t=2.44$. MA of $D s$ significantly greater than $D p, t=3.23$.

** $\quad$ MI of $D s$ significantly greater than $D b, t=2.44$. MI of $D s$ significantly greater than $D p, t=3.07$.

$\dagger$ PR of $D s$ significantly greater than $D b, \chi^{2}=5.85$. PR of $D s$ significantly greater than $D p, \chi^{2}=5.85$

\#* MA of $D s$ significantly greater than $D b, t=3.20$. MA of $D s$ significantly greater than $D p, t=3.26$

$\S \S \quad$ MI of $D s$ significantly greater than $D b, t=3.13$. MI of $D s$ significantly greater than $D p, t=3.28$.

I| $\|$ MA of $D s$ significantly greater than $D b, t=3.50$. MA of $D s$ significantly greater than $D p, t=3.89$.

\#\# MI of $D$ s significantly greater than $D b, t=3.50$. MI of $D s$ significantly greater than $D p, t=3.77$.

- MA of $D s$ significantly greater than $D p, t=2.85$

*** MI of $D s$ significantly greater than $D p, t=2.65$ 
TABle IX. Seasonal and between-year comparisons: dates, sample sizes, and infection indices of Dactylogyrus spp. on P. promelas at Oak Creek.*

\begin{tabular}{|c|c|c|c|c|c|c|c|c|c|c|}
\hline \multirow[b]{2}{*}{ Collection date } & \multirow{2}{*}{$\begin{array}{l}\text { No. of } \\
\text { fish }\end{array}$} & \multicolumn{3}{|c|}{ D. simplex } & \multicolumn{3}{|c|}{ D. bychowskyi } & \multicolumn{3}{|c|}{ D. pectenatus } \\
\hline & & PR & $\mathrm{MA} \pm 1 \mathrm{SD}$ & $\mathrm{MI} \pm 1 \mathrm{SD}$ & PR & $\mathrm{MA} \pm 1 \mathrm{SD}$ & $\mathrm{MI} \pm 1 \mathrm{SD}$ & PR & $\mathrm{MA} \pm 1 \mathrm{SD}$ & $\mathrm{MI} \pm 1 \mathrm{SD}$ \\
\hline Summer 2004 & 9 & 100.0 & $7.7 \pm 10.2$ & $7.7 \pm 10.2$ & $77.8 \dagger$ & $5.1 \pm 4.3 t$ & $6.6 \pm 3.7$ & 22.2 & $0.2 \pm 0.4$ & $1.0 \pm 0$ \\
\hline Fall 2004 & 5 & 100.0 & $3.6 \pm 1.5$ & $3.6 \pm 1.5$ & 20.0 & $0.6 \pm 1.3$ & $3.0 \pm 0$ & 40.0\|\| & $0.6 \pm 0.9$ & $1.5 \pm 0.7$ \\
\hline Spring 2005 & 16 & 87.5 & $4.9 \pm 3.7$ & $5.6 \pm 3.3$ & $87.5 \S$ & $2.2 \pm 2.0$ & $2.5 \pm 2.0$ & $50.0 \|$ & $0.5 \pm 0.5$ & $1.0 \pm 0$ \\
\hline Summer 2005 & 7 & 100.0 & $8.4 \pm 6.5$ & $8.4 \pm 6.5$ & 85.7 & $2.6 \pm 1.9 \#$ & $3.0 \pm 1.7$ & 14.3 & $0.1 \pm 0.4$ & $1.0 \pm 0$ \\
\hline Fall 2005 & 10 & 70.0 & $2.9 \pm 3.5$ & $4.1 \pm 3.5$ & 30.0 & $0.7 \pm 1.3$ & $2.3 \pm 1.5$ & 0 & 0 & 0 \\
\hline Spring 2006 & 8 & 100.0 & $12.6 \pm 8.1$ & $12.6 \pm 8.1$ & 62.5 & $1.1 \pm 1.1$ & $1.8 \pm 1.3$ & 37.5 & $0.5 \pm 0.8$ & $1.3 \pm 0.6$ \\
\hline Summer 2006 & 8 & 100.0 & $42.3 \pm 37.7$ & $42.3 \pm 37.7 * *$ & 100.0 & $10.6 \pm 8.9 \dagger \dagger$ & $10.6 \pm 8.9$ & $100.0 \%$ & $3.3 \pm 1.7 \S \S$ & $3.3 \pm 1.7$ \\
\hline Total & 63 & 92.1 & $11.0 \pm 18.6$ & $11.9 \pm 19.1$ & 69.8 & $3.2 \pm 4.8$ & $4.6 \pm 5.2$ & 38.1 & $0.7 \pm 1.2$ & $1.8 \pm 1.4$ \\
\hline
\end{tabular}

* $\quad \mathrm{MA}=$ mean abundance; $\mathrm{MI}=$ mean intensity; $\mathrm{PR}=$ prevalence; $\mathrm{SD}=$ standard deviation. Significance level $P<0.017$.

$+\quad$ In 2004, PR of $D b$ was significantly greater in summer than fall, $\gamma^{2}=4.38(P<0.05)$.

+ In 2004, MA of $D b$ was significantly greater in summer than fall, $t^{1}=2.90$.

$\S \quad$ In 2005 , PR of $D b$ was significantly greater in summer than fall, $\chi^{2}=8.99(P<0.05)$.

\| In 2005, PR of $D p$ was significantly greater in spring than fall, $\chi^{2}=7.22$.

\# In 2005, MA of $D b$ was significantly greater in summer than fall, $t^{l}=2.39$

- In spring, MA of $D s$ was significantly greater in 2006 than $2005, t^{1}=2.57$.

** In spring, MI of $D s$ was significantly greater in 2006 than $2005, t^{1}=2.34(P<0.05)$.

ti In 2006, MA of $D b$ was significantly greater in summer than spring, $t^{1}=3.00$

t5 In 2006, PR of $D p$ was significantly greater in summer than spring, $\chi^{2}=7.27$; In 2006, MA of $D p$ was significantly greater in summer than spring, $t^{1}=2.83$; In summer, PR of $D p$ was significantly greater in 2006 than 2005, $\chi^{2}=10.37$; In summer, PR of $D p$ was significantly greater in 2006 than $2004, \chi^{2}=6.53$

$\S \S$ In summer, MA of $D p$ was significantly greater in 2006 than $2004, t^{I}=4.98$; In summer, MA of $D p$ was significantly greater in 2006 than $2005, t^{l}=5.12$.

\|| $\|$ In fall, PR of $D p$ was significantly greater in 2004 than in $2005, \chi^{2}=4.61$.

At West Oak, abundance of $D$. simplex was significantly positively correlated with abundance of $D$. bychowskyi and $D$. pectenatus. Abundance of $D$. bychowskyi was significantly positively correlated with abundance of $D$. pectenatus. At Oak, abundance of $D$. simplex was significantly positively correlated with abundance of $D$. bychowskyi and D. pectenatus. Abundance of $D$. bychowskyi was significantly positively correlated with abundance of $D$. pectenatus.

\section{DISCUSSION}

The major contribution of this paper is the demonstration that host sex, size, and collection site are secondary to that of innate parasite species differences in fecundity and transmission in the structuring of Dactylogyrus populations and communities. This study is the first to demonstrate that among a community of Dactylogyrus spp., on a single host species, order of abundance

TABLE X. Community structure: collection dates, sample sizes, and infection indices of 3 Dactylogyrus spp. on P. promelas at Oak Creek.*

\begin{tabular}{|c|c|c|c|c|c|c|c|c|c|c|}
\hline Collection date & $\begin{array}{c}\text { No. of } \\
\text { fish }\end{array}$ & \multicolumn{3}{|c|}{ D. simplex } & \multicolumn{3}{|c|}{ D. bychowskyi } & \multicolumn{3}{|c|}{ D. pectenatus } \\
\hline Summer 2004 & 9 & $100.0 \dagger$ & $7.7 \pm 10.2$ & $7.7 \pm 10.2$ & $77.8 \$$ & $5.1 \pm 4.3 \S$ & $6.6 \pm 3.7$ & 22.2 & $0.2 \pm 0.4$ & $1.0 \pm 0$ \\
\hline Spring 2005 & 16 & 87.5 & $4.9 \pm 3.79$ & $5.6 \pm 3.3^{* *}$ & 87.5 & $2.2 \pm 2.0 \dagger \dagger$ & $2.5 \pm 2.0$ & 50.0 & $0.5 \pm 0.5$ & $1.0 \pm 0$ \\
\hline Summer 2005 & 7 & $100.0 t t$ & $8.4 \pm 6.5 \S \S$ & $8.4 \pm 6.5$ & 85.7 & $2.6 \pm 1.9\|\|$ & $3.0 \pm 1.7$ & 14.3 & $0.1 \pm 0.4$ & $1.0 \pm 0$ \\
\hline Fall 2005 & 10 & 70.0\#\# & $2.9 \pm 3.5$ & $4.1 \pm 3.5$ & 30.0 & $0.7 \pm 1.3$ & $2.3 \pm 1.5$ & 0 & 0 & 0 \\
\hline Total & 63 & 92.1 & $11.0 \pm 18.6$ & $11.9 \pm 19.1$ & 69.8 & $3.2 \pm 4.8$ & $4.6 \pm 5.2$ & 38.1 & $0.7 \pm 1.2$ & $1.8 \pm 1.4$ \\
\hline
\end{tabular}

\footnotetext{
$\begin{array}{ll}* & \text { MA }=\text { mean abundance; } \mathrm{MI}=\text { mean intensity; PR } \\ \dagger \quad & \mathrm{PR} \text { of } D s \text { significantly greater than } D p, \chi^{2}=11.46 . \\ + & \mathrm{PR} \text { of } D b \text { significantly greater than } D p, \chi^{2}=7.14 .\end{array}$

$\S \quad$ MA of $D b$ significantly greater than $D p, t=3.38$.

॥ PR of $D s$ significantly greater than $D b, \chi^{2}=6.67$.

\# MA of $D s$ significantly greater than $D b, t=3.31$. MA of $D s$ significantly greater than $D p, t=3.81$.

- MA of $D s$ significantly greater than $D b, t=2.58$. MA of $D s$ significantly greater than $D p, t=4.75$.

** $\quad$ MI of $D s$ significantly greater than $D b, t=4.19$.

$\dagger$ MA of $D b$ significantly greater than $D p, t=3.26$

$+\quad$ PR of $D s$ significantly greater than $D p, \chi^{2}=10.5$

$\S \S \quad$ MA of $D s$ significantly greater than $D p, t=3.35$.

\| ॥ MA of $D b$ significantly greater than $D p, t=3.31$.

\#\# PR of $D s$ significantly greater than $D p, \chi^{2}=10.77$.

- MA of $D s$ significantly greater than $D b, t=3.94$. MA of $D s$ significantly greater than $D p, t=4.20$.

*** MI of $D s$ significantly greater than $D b, t=3.69$. MI of $D s$ significantly greater than $D p, t=3.90$.

$\dagger \dagger$ MA of $D s$ significantly greater than $D b, t=2.31$. MA of $D s$ significantly greater than $D p, t=2.92$.

ft MI of $D s$ significantly greater than $D b, t=2.31$. MI of $D s$ significantly greater than $D p, t=2.92$.

$\S \S \S \mathrm{PR}$ of $D s$ significantly greater than $D p, \chi^{2}=7.27$.
} 
TABLE XI. $r$-Values of abundance correlations for 3 Dactylogyrus spp. at 3 sites in southeastern Nebraska.

$\begin{array}{lll}\text { D. simplex } & \text { D. bychowskyi D. pectenatus }\end{array}$

\begin{tabular}{llll}
\hline Elk Creek & & & \\
D. simplex & 1.00 & $0.57^{*}$ & $0.37^{*}$ \\
D. bychowskyi & & 1.00 & $0.39^{*}$ \\
D. pectenatus & & & 1.00 \\
West Oak & & & \\
D. simplex & 1.00 & $0.63^{*}$ & $0.83^{*}$ \\
D. pectenatus & & 1.00 & $0.45^{*}$ \\
D. pectenatus & & & 1.00 \\
Oak Creek & & & \\
D. simplex & 1.00 & $0.74^{*}$ & $0.72^{*}$ \\
D. bychowskyi & & 1.00 & $0.79^{*}$ \\
D. pectenatus & & & 1.00 \\
\hline
\end{tabular}

* Significance level at $P<0.017$.

(community structure) remained unchanged over time and space in a watershed.

The results lead to a failure to reject the null hypothesis of no difference in community structure (order of abundance) of 3 congeners coexisting within sites. In the present study, $D$. simplex was the most commonly occurring species of gill parasite on $P$. promelas, followed by $D$. bychowskyi and $D$. pectenatus. Koskivaara et al. (1991) found 2 Dactylogyrus spp. dominated a complex community in 3 Finnish lakes, though the order of PR of the less common species varied. The low MI of D. pectenatus in the present study is consistent with a low MI found by King and Cone (2009). The results thus reveal inherent differences between congeners infecting the same host species, differences that must be related to reproduction, development, and parasite contributions to transmission.

The community of gill parasites found on $P$. promelas in the present study also was consistent with previously published reports from Elk and West Oak (Weichman and Janovy, 2000) and with a parasite fauna in its native range (Hoffman, 1999). These results add to the Weichman and Janovy (2000) work, by the addition of a third study site and 2 additional years, thus strengthening the contention that in this system order of abundance of Dactylogyrus spp. remained stable over time and space. Thus, some facet of the biology of $D$. simplex contributes to its high abundance and prevalence when compared to other Dactylogyrus spp. on the same hosts in the same environments.

In the first-order streams, Elk and West Oak, larger P. promelas had somewhat higher abundances of Dactylogyrus spp. than smaller individuals. At West Oak, larger $P$. promelas had somewhat higher species richness than smaller hosts. At Oak, there were no correlations between STL and Dactylogyrus spp. abundance or richness. These results suggest that host size plays a somewhat greater role in determining Dactylogyrus abundance at first-order streams than in second-order streams. Relationships between host size and Dactylogyrus spp., abundance (Öztürk, 2002; Aydogdu, 2003; Öztürk and Altunel, 2006), and richness (Guégan et. al., 1992) have been demonstrated in some systems. In other systems, however, no relationship between host size and Dactylogyrus spp. abundance was demonstrated (King and Cone, 2009). However, the generally inconsistent and weak nature of these correlations indicate that Dactylogyrus spp. infections in this system are independent of host STL. There are also no consistent, significant differences between male and female fish in PR or MA of D. simplex, D. bychowskyi, or D. pectenatus, indicating infection of $P$. promelas with Dactylogyrus spp. is independent of host sex. Barse (1998) also found no relationship between host sex and Salsuginus sp. prevalence or density. Indeed, there is virtually no previous work with dactylogyrids demonstrating significant abundance or prevalence differences according to host sex. For the present, the general rule probably should be that Dactylogyrus spp. do not discriminate between host sexes, regardless of potential secondary sexual characters in those hosts.

Previous population studies examined seasonal occurrence of a Dactylogyrus sp. (Aydogdu et al., 2003; Lamková et al., 2007), but few examined seasonal changes over more than 1 yr (Öztürk and Altunel, 2006). Dzika (1987) studied a community of 4 Dactylogyrus spp. for a 2-yr period and found that prevalence and abundance was lowest between October and November and increased in early spring, with the particular dynamics being species specific. Pojmańska (1995) confirmed Dzika's work and observed relationships between occurrence and reproductive dynamics of Dactylogyrus spp. and the long-term climate conditions of the species' region of origin. The current study, to our knowledge, is the first to examine seasonal dynamics of a complex Dactylogyrus community on a Native North American host species at multiple sites, over multiple years.

The results lead to the rejection the null hypothesis of no difference in abundance, intensity, and prevalence among 3 congeners coexisting within 3 sites. They show no consistent patterns of seasonal fluctuations in either abundance or prevalence in any of the sites or for any of the 3 Dactylogyrus spp. studied, although abundances and prevalences tend to be highest in summer collections. The elevated parasite infections in summer agree with other studies, which note the favorable influence of the warmer season on reproduction and survival of Dactylogyrus spp. (Pojmańska, 1995). In the current study, the 3 streams are subject to periodic flooding with major changes in flow rates and water levels, although snail populations suggest that Elk, with both Helisoma trivolvis and Physa sp. populations, is in some way abiotically different from the West Oak and Oak, both of which have only Physa sp. populations. Annual precipitation evidently influences transmission dynamics, however, because between-year differences, within a particular site, are generally greater than within-year differences at those same sites. Dactylogyrus species populations at West Oak were the most stable between years, followed by Oak and Elk.

In every collection at West Oak, PR of all 3 Dactylogyrus spp. was greater than zero. For all 3 Dactylogyrus spp., total PR, MA, and MI were highest at West Oak. The observed differences in Dactylogyrus spp. populations among sites were not consistent over $3 \mathrm{yr}$; however, there was an important, though not statistically significant, trend in which total MA and MI of all 3 species was highest at West Oak. Total PR of D. bychowskyi and $D$. pectenatus was also highest at West Oak, though total PR of $D$. simplex was highest at Oak, the fastest flowing and most variable of the 3 sites. The trend, in which species are more abundant and in higher PR at West Oak, indicates that some aspect of the environment at West Oak is more conducive to infection with Dactylogyrus spp. than it is at the other sites. Dactylogyrus simplex differs in some fundamental way from its congeners, 
highlighting the importance of studying multiple population parameters in order to understand congeneric species' biology. Further investigation of abiotic site differences will be necessary to determine the particular role of site in forming the Dactylogyrus spp. populations.

Rohde (1989) asserted that host-parasite systems are good models for investigating evolutionary and ecological mechanisms that contribute to biological diversity. Dactylogyrus spp. and their cyprinid hosts are particularly good systems for this work because both are exceedingly diverse and widely distributed, and multispecies infections are common. For example, Šimková et al. (2004), using molecular techniques, determined that much of the diversification within the Dactylogyrus sp.-cyprinid fishes model was a result of intrahost speciation, a phenomenon they noted had rarely been recognized in host-parasite associations, thereby highlighting the power of this system in the study of evolution and biological diversity. The current small-scale, ecological study provides evidence of population and community dynamics in nature reveals congeners differ in their ability to infect, thereby supporting the conclusions of intrahost speciation based on molecular phylogenetic data by Šimková et al. (2004).

\section{ACKNOWLEDGMENTS}

We thank Dr. Matthew Bolek, Oklahoma State University, for assistance in fish collection and invaluable discussions on the topic. This work was supported by grants from the School of Biological Sciences, University of Nebraska-Lincoln, Lincoln, Nebraska. The authors would like to thank Dr. Gerald Esch and two anonymous reviewers for improvements on an earlier draft of this manuscript.

\section{LITERATURE CITED}

Aydogdu, A., A. Kostadinova, and M. Fernandez. 2003. Variations in the distribution of parasites in the common carp, Cyprinus carpio, from Lake Iznik, Turkey: Population dynamics related to season and host size. Helminthologia 40: 33-40.

Barse, A. M. 1998. Gill parasites of mummichogs, Fundulus heteroclitus (Teleostei: Cyprinodontidae): Effects of season, locality, and host sex and size. Journal of Parasitology 84: 236-244.

Bush, A. O., K. D. Lafferty, J. M. Lotz, and A. W. Shostak. 1997. Parasitology meets ecology on its own terms: Margolis et al. revisited. Journal of Parasitology 83: 575-583.

DzIKA, E. 1987. Annual occurrence dynamics of common monogeneans on the gills of bream from Lake Goslawskie (Poland). Acta Parasitologica Polonica 32: 121-137.

Gibson, D. I., T. A. Timofeeva, and P. I. Gerasev. 1996. A catalogue of the nominal species of the genus Dactylogyrus Diesing, 1850 and their host genera. Systematic Parasitology 25: 3-48.

Guégan, J.-F., A. Lambert, C. Lévêque, C. Combes, and L. Euzet. 1992. Can host body size explain the parasite species richness in tropical freshwater fishes? Oecologia 90: 197-204.

Hoffman, G. L. 1999. Parasites of North American freshwater fishes, 2nd ed. Comstock Publishing Associates, Ithaca, New York, 539 p.

Janovy, J., JR., S. D. SNyder, and R. E. Clopton. 1997. Evolutionary constraints on population structure: The parasites of Fundulus zebrinus (Pisces: Cyprinodontidae) in the South Platte River of Nebraska. Journal of Parasitology 83: 584-592.

KING, S. D., AND D. K. Cone. 2009. Infections of Dactylogyrus pectenatus (Monogenea: Dactylogyridae) on Larvae of Pimephales promelas (Teleostei: Cyprinidae) in Scott Lake, Ontario, Canada. Comparative Parasitology 76: 110-112.

Koskivaara, M., E. T. Valtonen, and M. Prost. 1991. Dactylogyrids on the gills of roach in central Finland: Features of infection and species composition. International Journal for Parasitology 21: 565572.

Kritsky, D. C., V. E. Thatcher, And W. A. Boeger. 1986. Neotropical Monogenea. 8. Revision of Urocleidoides (Dactylogyridae, Ancyrocephalinae). Proceedings of the Helminthological Society of Washington 53: 1-37.

Lamkovâ, K., A. Šimková, M. Palíková, P. Jurajda, and A. Lojek. 2007. Seasonal changes of immunocompetence and parasitism in chub (Leuciscus cephalus), a freshwater cyprinid fish. Parasitology Research 101: 775-789.

MaYes, M. 1976. The adult platyhelminth parasites of Nebraska fishes. Ph.D. Dissertation. University of Nebraska-Lincoln, Lincoln, Nebraska, 207 p. . 1977. New species of Gyrodactylus and Dactylogyrus Trematoda Monogenea from fishes of Nebraska, USA. Journal of Parasitology 63: $805-809$.

Mizelle, J. D. 1937. Ectoparasites of the blunt-nosed minnow (Hyborhynchus notatus). American Midland Naturalist 18: 612-621.

Murith, D., and M. Beverley-Burton. 1985. Salsuginus BeverleyBurton, 1984 (Monogenea: Ancyrocephalidae) from Cyprinodontoidei (Atheriniformes) in North America with descriptions of Salsuginus angularis (Mueller, 1934) Beverley-Burton, 1984 from Fundulus diaphanous and Salsuginus heterocliti n. sp. from $F$. heteroclitus. Canadian Journal of Zoology 63: 703-714.

Nelson, J. S. 2006. Fishes of the world, 4th ed. John Wiley \& Sons, Hoboken, New Jersey, $601 \mathrm{p}$.

ÖZTürk, M. O. 2002. Metazoan parasites of the tench (Tinca tinca L.) from Lake Uluabat, Turkey. Israel Journal of Zoology 48: 285-293.

- , AND F. N. Altunel. 2006. Occurrence of Dactylogyrus infection linked to seasonal changes and host fish size on four cyprinid fishes in Lake Manyas, Turkey. Acta Zoologica Academiae Scientiarum Hungaricae 52: 407-415.

Pflieger, W. L. 1997. The fishes of Missouri. Missouri Department of Conservation, Jefferson City, Missouri, 372 p.

PojmańSKA, T. 1995. Seasonal dynamics of occurrence and reproduction of some parasites in four cyprinid fish cultured in ponds. II. Monogenea. Acta Parsitologica 40: 79-84.

Pritchard, M. H., and G. O. W. Kruse. 1982. The collection and preservation of animal parasites. University of Nebraska Press, Lincoln, Nebraska, $141 \mathrm{p}$.

Rohde, K. 1989. Simple ecological systems, simple solutions to complex problems. Evolutionary Theory 8: $305-350$.

Šimkoví, A., S. Morand, E. Jobet, M. Gelnar, and O. Verneau. 2004. Molecular phylogeny of congeneric monogenean parasites (Dactylogyrus): A case of intrahost speciation. Evolution 58: 1001-1018.

SoKal, R. R., and F. J. Rohlf. 1995. Biometry: The principles and practice of statistics in biological research, 3rd ed. W. H. Freeman and Company, New York, New York, 887 p.

Weichman, M. A., AND J. JANOVY, JR. 2000. Parasite community structure in Pimephales promelas (Pisces: Cyprinidae) from two converging streams. Journal of Parasitology 85: 654-656. 